\title{
Infectious diseases - the next big challenge
}

In September 2016 a woman in her 70s died in Nevada, USA from an infection with carbapenem-resistant Enterobacteriaceae (CRE), which was resistant to all antibiotics available in the States. ${ }^{[1]}$ The woman had apparently returned from an extended trip to India, where she had received treatment for a fractured femur and hip problems, with multiple hospital admissions. The CRE isolated from her wounds in August that year was Klebsiella pneumoniae, which proved resistant to all 26 antibiotics that it was tested against. A specific enzyme, New Delhi metallo-beta-lactamase, making bacteria resistant to a broad range of antibiotics, was detected in one of her wounds, according to the Centers for Disease Control and Prevention, USA.

Multidrug-resistant K. pneumoniae has been described by the World Health Organization as an 'urgent threat to human health'

In May 2016, international newspapers carried stories of a 'superbug resistant to "antibiotic of last resort", which was isolated in the USA. The CRE in this instance was isolated from the urine of a 49-year-old woman in Pennsylvania. In this case, the bacterium was a strain of Escherichia coli resistant to the antibiotic colistin, widely regarded as the 'antibiotic of last choice. The authors of this article ${ }^{[2]}$ stated that 'The recent discovery of a plasmid-borne colistin resistance gene, $m r c-1$, heralds the emergence of a truly pan-drug resistant bacteria'. This was the first time that this colistin-resistant strain was found in a person in the USA. The woman survived the infection, but someone older or with comorbidities may not have done.

CREs are known in India, now in the USA, and they are right here in South Africa. ${ }^{[3]}$ What is particularly worrying is that these resistant strains are being isolated in relatively common infections - an apparent osteomyelitis from a femur fracture in an elderly woman and from a urinary tract infection in a relatively young woman. The story of multidrug- and extreme-drug-resistant tuberculosis is well known and has been a problem for many years, albeit with slow buyin from the larger pharmaceutical companies in terms of developing new treatments.

But the emergence of resistant strains of more commonly encountered bacteria in the developed world may change this, as multidrugresistant strains of commonly encountered bacteria cause illness and death across the world. Metacillin-resistant Staphylococcus aureus has been with us for many years now. My father fell prey to it in a private Cape Town hospital $>6$ years ago and I first encountered it as a locum in UK hospitals $>25$ years ago. We did not pay enough attention then, and now developing new - and more expensive - antibiotics is not the answer.

Doctors in primary care continue to prescribe, often at the patient's request, unnecessary antibiotics. In hospitals without good infection control and antibiotic stewardship policies doctors prescribe inappropriate antibiotics - my father was first treated with amoxicillin/ clavulanic acid (Augmentin) when it became obvious that he had a severe wound infection.

We urgently need to stop unnecessary and inappropriate prescription of antibiotics across the board. And we also need to put pressure on manufacturers of 'antiseptic' household cleaners and hand washes to stop producing and marketing these. Public education campaigns explaining that simple handwashing with ordinary soap and water, and that most infections in primary care are self-limiting and caused by viruses, are urgently needed. Shocking headlines in newspapers about serious hospital infections are not sufficient. People need to realise that this is something that affects their daily lives and could result in the death of a loved one from a common - and previously treatable infection.

\section{Bridget Farham \\ Editor \\ ugqirha@iafrica.com}

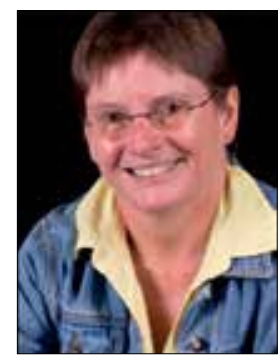

1. US woman dies of infection resistant to all 26 available antibiotics. https://medicalxpress.con/ news/2017-01-woman-dies-infection-resistant-antibiotics.html (accessed 16 January 2017).

2. Boyles TH, Naicker V, Rawoot N, Raubenheimer PJ, Eick B, Mendelson M. Sustained reduction in antibiotic consumption in a South African public sector hospital: Four-year outcomes from the Groot Schuur Hospital antibiotic stewardship programme. S Afr J Med 2017;107(2):115-118. http://dx.doi. org/10.7196/SAMJ.2017.v107i2.12067

3. McGann P, Snesrud E, Maybank R, et al. Antimicrob Agents Chemother 2016;60(7):4420-4421. http:// dx.doi.org/10.1128/AAC.01103-16

S Afr Med J 2017;107(2):91. DOI:10.7196/SAMJ.2017.v107i2.12324 